\title{
Testing the Neoclassical Model of Regional Economic Growth: A Panel Data Approach across the Finnish Provinces, 1973-1996
}

\author{
Petteri Mäki-Arvela*
}

\begin{abstract}
This study assesses the degree to which the variation of regional growth rates in Finland during the period 1973-1996 is consistent with the neoclassical view of growth. Panel data on Finnish provinces are examined with several estimation techniques and the obtained results are tested for their sample and model sensitivity. A region's investment rate, population growth rate, and the rate of technological progress are found to be reliable predictors of output per capita, but only when the growth model is augmented to include human and public capital accumulation, as well as initial conditions among regions. This suggests a need to examine the links between regional economic growth and the accumulation of new forms of capital more carefully.
\end{abstract}

\section{INTRODUCTION}

After a long period of quiescence, the field of growth economics has reawakened in the last decade as an extremely active area of research. Economists have come to understand that the determinants of long-run economic growth are crucial issues in the field of economics, far more important than the mechanisms of short-term business cycles or measuring the magnitude of temporary monetary and fiscal policy effects. Policy makers at all levels of government have increasingly focused their attention on the means necessary to raise the long-term rate of economic growth and social well-being.

A plethora of international research has already investigated the factors of economic growth in a multinational context. By contrast, the amount of regional growth research has been far more limited. This is somewhat surprising, because the analysis of regional growth is a focal point in regional economics, and understanding how and why regional output grows is critical for the development of an effective regional policy. In Finland the disparities in regional growth rates and the specific factors causing very divergent paths of regional development have always been a major policy issue. Despite that, the corpus of economic research in Finland has been dominated by distinct monetary policy topics. Studies on economic growth, central to the study of macroeconomics, have had only a very limited role, especially so among regional analysis. This is the case despite the fact that we have reason to believe that regional growth empirical studies in Finland have scientific relevance and applicability not only to Finland herself, but also to several other highly industrialized countries, both with as well as without the

"Department of Economics, University of Turku, Finland. The author gratefully acknowledges financial support by research grants from the University of Turku Foundation and the Finnish Cultural Foundation. The helpful comments of Professor Hannu Koiranen and two anonymous referees are also gratefully acknowledged. 
characteristics of the Nordic type of economy. This is because the overall growth patterns of the Finnish economy have had a strong resemblance to various other western economies, both in terms of business fluctuations as well as growth trends (see, for instance, Andrés, Doménech, and Molinas 1996 or Crafts and Toniolo 1996). Particularly significant in the mainstream neoclassical context is the fact that there appears to have been a clear tendency of so-called $\beta$ - and $\sigma$-convergence among the regional output per capita ratios in Finland, although this development has been decreasing and has almost completely diminished during recent decades (compare with Kangasharju 1998, Loikkanen, Laakso, and Sullström 1998, MäkiArvela 2002, and Pekkala 1999). This apparent compatibility with predictions of the neoclassical growth model has been the main motivation for this study, which will focus on some of the key regularities in the Finnish regional growth process and test them primarily within the well-known neoclassical framework.

The Solowian growth model that shall form the theoretical basis of this paper has played an essential role in the development of all mainstream empirical growth modeling. The model emphasizes how growth arises from the accumulation of capital and how each economy is characterized by a specific steady state that is independent of the initial conditions of the regional economies. One of the most influential hallmarks of the applied work within this research tradition is the study of Mankiw, Romer, and Weil (1992), henceforth M-R-W. In their illuminating article, the traditional Solow growth model was for the first time formally augmented in an attainable way so as to include human capital in addition to traditional physical capital. The exposition made by M-R-W clarifies many of the underlying ideas that almost all growth regressions have since then held in common. Accordingly, the main premises to the applied approach of this paper can also largely be inferred from those of M-R-W.

Our discussion will begin by reviewing the basic properties and formulation of the M-R-W type neoclassical growth model. Once that has been accomplished, we shall present the data applied in empirical analysis, after which results from different types of estimations are compared and then thoroughly tested for their sensitivity. Finally, some overall inferences are drawn and topics for further discussion are tentatively put forth with a more personal view of the main results.

\section{THEORETICAL BACKGROUND}

\section{Basis for the Regional Growth Research}

In this article, we shall concentrate entirely on regional growth rates instead of the current output levels. This is because we assume that different types of variables that best describe the level of economic development are usually highly correlated, with the result that this might lead to a false conclusion about the causal relations of variables. This problem is most evident in development economics, where several factors recognized in industrialized countries are (often falsely) assumed to be the cause of growth instead of being mere by-products of it. This type of level accounting, thus, tends to lead to few implications for policy. 
Following McCullum (1996), we may state that the neoclassical model is first and foremost designed to provide understanding about growth, not about the prevalent differences in income levels, which may be the result of history and other external factors that are not at all feasibly integrated into model of traditional growth theory.

In choosing to confine the research of this paper on the lines laid down by the neoclassical research tradition, we deliberately restrain those factors emphasized by the alternative endogenous growth models outside the focus of this study. This is not only because it is quite easy to justify the use of an explicit, wellknown theoretical model, but also because there are several research design considerations showing why neoclassical assumptions should be especially applicable to regional analysis. For example, neoclassical models typically assume that all economies are considered to have access to identical production technologies and are very homogeneous in relation to their consumer preferences and their institutional settings. At the regional level, the free flow of technology and small variations in legal settings, political institutions, and cultural factors, offer an opportunity to analyze the development of very similar kinds of economies, unlike those found in the international arena. On the other hand, regions as very open economies (unlike the assumption of the basic closed-economy Solow model) may experience that the free mobility of capital and work force will create endogeneity in their population growth and investment patterns. All of these inappropriate inferences should be carefully avoided when using regional data.

\section{Neoclassical Growth Model}

Let us begin by briefly viewing the M-R-W-type neoclassical Solow-Swan growth model augmented to include human capital. We will further augment this model and work exclusively with it here. Let the production function be a CobbDouglas production function with constant returns to scale, ${ }^{1}$

$$
Y_{t}=K_{t}^{\alpha} H_{t}^{\beta}\left(A_{t} L_{t}\right)^{1-\alpha-\beta},
$$

where $Y$ is real output, $K$ is the stock of physical capital, $H$ is the stock of human capital, L is raw labor, A is the level of labor-augmenting (Harrod neutral) technology (comprising the overall efficiency of the economy), and $t$ refers to time in years. We assume that $\alpha+\beta<1$, so that there are constant returns to factor inputs jointly and decreasing returns separately.

Raw labor $\mathrm{L}$ and labor-augmenting technology $\mathrm{A}$ are assumed to grow according to the following functions:

$$
\begin{aligned}
& L_{t}=L_{0} e^{n t}, \\
& A_{t}=A_{0} e^{g t} F^{\psi},
\end{aligned}
$$

${ }^{1}$ Alternative growth models that incorporate nonrivalry and/or externalities imply that the size of an economy may influence its long-run growth rate. Such implied scale effects run counter to empirical evidence found at the country level, as presented, for example, at Jones (1995) and Backus, Kehoe, and Kehoe (1992). 
where $\mathrm{n}$ is the exogenous rate of growth of the labor force, $\mathrm{g}$ is the exogenous rate of technological progress and $\mathrm{F}$ is the vector of other parameters assumed to affect A. Thus, our efficiency variable A differs from that used by $M-R-W$ in that it depends not only on exogenous technological improvements, but also on factors included in vector $\mathrm{F}$. These factors are the rate of primary production with respect to GDP, investments on public capital, and political factors. There is reason to believe that this kind of modification is particularly relevant to the empirical study of economic growth within national regions, since regions are often not that homogeneous in relation to their structure of production, as the basic neoclassical model would assume. The differences between the efficiency of the productive sector of the regions may depend heavily on the structure of production, public infrastructure investments, and political factors.

Akin to the standard notation, the model assumes that a constant fraction of output, $s$, is saved. The savings ratio is assumed to be exogenously determined either by savers' preferences or by governmental policy. Thus, capital accumulation is determined by the savings rate, $s_{k}$ being the fraction of income invested in physical capital and $s_{h}$ the fraction invested in human capital. Defining $k$ as the stock of physical capital per effective unit of labor, $\mathrm{k}=\mathrm{K} / \mathrm{AL}$, and $\mathrm{h}$ as the stock of human capital per effective unit of labor, $h=H / A L$, and $y$ as the level of output per effective unit of labor, $y=Y / A L$, the evolution of $k$ and $h$ are governed by

$$
\begin{aligned}
& k_{t}^{Y}=s_{k} y_{t}-(n+g+\delta) k_{t}, \\
& h_{t}^{Y}=s_{h} y_{t}-(n+g+\delta) h_{t},
\end{aligned}
$$

where $\delta$ is the rate of depreciation. We are assuming that the same production function applies to physical and human capital as well as to consumption. In addition, we are assuming that human capital depreciates at the same rate as physical capital.

In the steady state, the levels of physical and human capital per effective worker are constant. As M-R-W (1992, p. 417) have shown, $k$ (the stock of physical capital per effective unit of labor) and $h$ (the stock of human capital per effective unit of labor) converge to their steady-state values (represented by an asterisk superscript) as

$$
\begin{aligned}
& k^{*}=\left(s_{k}^{1-\beta} s_{h}^{\beta} / n+g+\delta\right)^{1 /(1-\alpha-\beta)} \text { and } \\
& h^{*}=\left(s_{k}^{\alpha} s_{h}^{1-\alpha} / n+g+\delta\right)^{1 /(1-\alpha-\beta)} .
\end{aligned}
$$

Thus, for both physical and human capital, the steady-state capital-labor ratio is related positively to the rate of savings and negatively to the rates of population growth, technological development, and capital depreciation. Furthermore, in the steady state, the capital stock grows at same rate as output, so the capitalto-income ratio is constant. Thus, the steady-state level of income depends on the rates of saving and population growth. On the other hand, the steady-state growth rate of output per worker has a constant value $g$, the exogenous component of technological progress in the efficiency variable $\mathrm{A}$. 
To formalize the growth equation, we substitute Equations 6 and 7 into the production function and approximate it around the steady state. Finally, substituting for $\mathrm{y}^{*}$ and rearranging terms gives (see Knight, Loyaza, and Villanueva 1993, p. 519):

$$
\begin{gathered}
y_{t}-y_{0}=\theta(\alpha+\beta / 1-\alpha-\beta)(n+g+\delta)+\theta(\alpha / 1-\alpha-\beta) s_{k}+\theta(\beta / 1-\alpha-\beta) s_{h}+ \\
\theta \psi F+\theta y_{0}+\left[\theta\left(t_{0}+r\right) g+e^{-\lambda r} r g\right]+\theta A_{0} .
\end{gathered}
$$

where $\theta=1-\mathrm{e}^{-\lambda t}$. Note that the linearization of the transition path around the steady state leads to

$$
\mathrm{dy}_{\mathrm{t}} / \mathrm{d}_{\mathrm{t}}=\lambda\left(\mathrm{y}^{*}-\mathrm{yt}\right),
$$

where parameter $\lambda=(n+g+\delta)(1-\alpha-\beta)$ defines the speed of convergence (Knight, Loyaza, and Villanueva 1992). The reason for the transitional dynamics is that the relatively poor economy must have lower stocks of physical and human capital. Hence, the marginal product of extra capital is higher in this economy and for a given rate of investment its growth pace will be more rapid. Thus, in this augmented Solow model the growth of output is a function of the determinants of the ultimate steady state and the level of initial output. This is because we wish to dismiss the unrealistic assumption that regions would already be in their steady state. The result is the standard form of growth equation, which is also known as conditional convergence regression.

If the speed of convergence $\lambda$ is positive, as expected, we can predict the signs of the coefficients in Equation 8. The first coefficient indicates that for given $\alpha, \beta, \delta$, and $g$, the rate of per capita output is negatively related to the growth of population. The second and third coefficients indicate that the higher the investment rates in physical and human capital are, the more rapidly output grows. The fourth coefficient is positive (negative) if the elasticity of other factors, $\psi$, affecting $A$ is positive (negative). The fifth term simply indicates that the output of regions grows faster if they are initially below their steady-state growth path, assuming common steady-state levels. This phenomenon is generally referred to as conditional convergence (see M-R-W 1992; Barro and Sala-i-Martin 1992; Sala-i-Martin 1996). The sixth term suggests the presence of a time-specific effect on growth from period $t=t_{0}$ to $t=t_{0}+r$. The last term contains $A_{0}$, which represents all the unobserved region-specific efficiency effects.

\section{EMPIRICAL BACKGROUND}

\section{The Panel Growth Model}

Empirical studies of long-run economic growth, both at international and interregional levels, have usually utilized cross-sectional data. As said above, the number of econometric analyses of regional growth in Finland has been very limited, and the studies have usually examined the development of only some growth factors and only some areas considered to be representative enough. This 
has forced us to use some rather restrictive assumptions concerning econometric specifications, namely, that the region-specific factor can be ignored and that timespecific effects are irrelevant too. Fortunately, panel data are available for most variables of interest on long enough time spans. This allows one to increase the degrees of freedom in the models to acceptable levels and to exploit the additional information contained in panel data, for instance, to check for omitted variables that are persistent over time.

As said, the main objective of this paper is to re-evaluate the empirical performance of the M-R-W model, but this study also extends the M-R-W analysis in several ways. First, a panel of time series cross-sectional data is explored in order to determine and measure the significance of such region-specific effects that are assumed to emerge in a cross-sectional approach. An important example of such an effect, the role of the unobserved effects of heterogeneity on the initial efficiency of the regional economies, is often mentioned as a potential source of estimation bias when correlated with any of the other regressors. Second, an underlying argument is that the use of panel data is the best available approach to resolve several other econometric problems that are likely to emerge in an M-R-W type of growth regression. Starting with the problems of heteroskedasticity and serial correlation in the growth model, we see it is necessary to apply the feasible generalized least squares method to our panel data. Simultaneity biases, i.e., concerns that the regressors are likely to be endogenous and contain measurement errors, are handled by the use of a set of instruments. Moreover, the effect of the presence of unobserved initial technological efficiency of the regional economies, which threatens to bias the estimates when correlated with regressors, is tested and avoided with the inclusion of regional dummies in the regression. Third, we find it desirable to augment the M-R-W somewhat further by assuming that economic growth is influenced by two other potentially important factors, namely, the accumulation of public or infrastructure capital, and local political preferences. These new variables added to the growth model are considered especially relevant in an economic environment with the distinct features of the Scandinavian economic model. Under such circumstances, the public sector and the centralized tripartite type of decision-making process (also known as social corporatism) have traditionally had a strong economic impetus that has been often disregarded in formal growth modeling prior to this study. Fourth, we shall also consider several other factors frequently mentioned in the literature as potentially important factors of growth. Examples of these are tertiary education, transportation networks, government finance (social spending, taxes, and debt), and agglomeration effects. We shall test the statistical relevance of these factors in the Finnish regional growth process by using them as so-called condition variables within the sensitivity analysis of our growth model, drawing on influential work by Levine and Renelt (1992), presented at the end of this article.

Equation 8 suggests a natural specification for the regression that can be used to study determinants of output growth, using panel data for Finnish regions. Let us write a more general form of Equation 8 for a given region i: 


$$
\begin{aligned}
& y_{i, t}-y_{i, t-1}= \theta_{1}\left(n_{i, t}+g+\delta\right)+\theta_{2} s_{k_{i, t-1}}+\theta_{3} s_{h_{i, t-1}}+\theta_{4} F_{i, t-1}+\lambda^{*} y_{i, t-1}+ \\
& \zeta_{t}+\mu_{i}+\varepsilon_{i, t},
\end{aligned}
$$

where $\theta_{1}, \ldots, \theta_{4}$ and $\lambda^{*}$ are parameters to be estimated, $\zeta_{t}$ represents time-specific effect, $\mu_{\mathrm{i}}$ represents region-specific effect, and $\varepsilon_{\mathrm{i}, \mathrm{i}}$ is the disturbance term. All variables are described in Table 1.

In an orthodox neoclassical context, any differences in regional productivity growth are seen as being fundamentally the result of the gains accruing from a progressive reduction in an initial interregional or intraregional suboptimal allocation of resources. Since improvements on the interregional allocation of resources are inextricably bound up with the interregional (or intersectoral) movement of labor, unemployment and differences in unemployment rates are in the neoclassical model considered only temporal. According to the model, the evolution of employment should follow a path similar to that of productivity growth (see, e.g., McCombie 1988). Thus, regional employment should evolve in the same way as Equation 10 depicts. To test the realism of this view, we will estimate the change in the level of employment using the very same model, the only alteration being that the level of initial productivity is replaced with the initial level of employment. Moreover, the underlying idea of running this alternative model successively through the entire study is to ensure that the reader gains an impression of why and how some results are at the end of the day considered fragile, while the model of our main emphasis (i.e., our model of regional GDP growth) must be considered robust.

\section{Description of the Data}

Our sample extends over the period from 1973 to 1996 . We are working with non-overlapping time intervals, selected to represent circumstances in macroeconomic terms as balanced as possible so as to avoid any significant cyclical influences. Given the strong cyclical behavior of the Finnish economy, we have attempted to avoid observations of deep recession periods such as during the oil crises of the 1970s and the deep recession of the early 1990s. The latest accessible observations were those of the year 1996 and the earliest those of 1973. This sample period was divided into two subperiods of almost identical length, so that our cross sections correspond to the years 1973,1980,1988, and 1996. The regional unit of observation is here a province, a regional division obtainable in national statistics that in the best way meets the criteria of a homogeneous economic region, as presupposed in neoclassical growth theory. ${ }^{2}$

We will now explain each of the variables incorporated into our empirical model in greater detail. The variables and their sample statistics are shown in Table 1.

2For a more detailed discussion of the criteria of the homogeneous economic region and regional division in Finland, see Mäki-Arvela (2002). 
TABLE 1

Variables and their Sample Statistics

\begin{tabular}{|c|c|c|}
\hline Variable & Mean & Standard Deviation \\
\hline Productivity growth DY $(\log 1990 \text { FIM) })^{a}$ & 0.0576 & 0.0404 \\
\hline Employment growth DE (\% population) ${ }^{\mathrm{a}}$ & 0.1091 & 3.3355 \\
\hline Population growth ${ }^{b} n$ & 13.664 & 28.378 \\
\hline Investment rate $s_{k}$ (avereage $\% / G D P$ ) ${ }^{c}$ & 29.688 & 2.657 \\
\hline Human capital growth $s_{h}(\% \text { pop. with secondary ed. })^{b}$ & 9.1485 & 2.4447 \\
\hline Primary production $\mathrm{pp}(\% \text { of GDP })^{\mathrm{a}}$ & 13.758 & 7.011 \\
\hline Public capital pc (per capita 1990 FIM) ${ }^{\text {b }}$ & 4100.2 & 1613.2 \\
\hline Left-wing councilors ps (\%) & 37.030 & 7.1011 \\
\hline Tertiary education growth (\% pop.) ${ }^{b}$ & 2.0939 & 0.97145 \\
\hline Highways (index value) & 1.199 & 0.026 \\
\hline Railroads (index value) ${ }^{\mathrm{a}}$ & 1.377 & 0.054 \\
\hline Social expenditure (per capita 1990 FIM) ${ }^{b}$ & 7218.0 & 2145.9 \\
\hline Public debt (per capita 1990 FIM) & 3866.1 & 528.8 \\
\hline Local income tax rate $(\%)^{b}$ & 16.105 & 0.95505 \\
\hline Population density (inhabitant $/ \mathrm{km}^{2}$ ) & 26.967 & 30.529 \\
\hline
\end{tabular}

${ }^{2}$ Data sources are issues of Statistical Yearbook of Finland (Statistics Finland) and issues of Seutukuntakatsaus [Survey of NUTS 4-regions in Finland] (Statistics Finland).

bata sources are issues of Statistical Yearbook of Finland (Statistics Finland).

'Data sources are issues of Regional Accounting (Statistics Finland).

${ }^{\mathrm{d}}$ Data source is Lahti (1988).

The primary dependent variable is the difference of real GDP per capita at factor cost by province, indicated as.DY. Whereas we also want to measure the effects of growth rates of capital and total factor productivity on employment, we will use the difference of the share of the employed labor force, DE, as another dependent variable. This is justified on the grounds that the amount of the labor force varies over time due to population growth and changes in the work participation rates, as well as to effects of migration. We may assume that productivity growth and real wage rate should be highly correlated. Thus, migration increases output per capita figures when potential unemployment is reduced due to immigration. This development could lead to false conclusions as regards the welfare dimension of the observed development, if we did not simultaneously observe the development in employment.

As noted in Equation 10, the first independent variable is the growth rate of the population, measured here by province at year-end levels, plus the two exogenous components, $g+\delta$. Since there is no reliable way of approximating the rates of technological progress and capital depreciation and because we do not want to use any ad hoc values for them, we must assume that the constant term and other parameters will reflect their effect too. Another point to note is that $g$ and $\delta$ are likely to vary across regions with the result that any conventional estimation of the model would ignore this subtlety. Therefore, the possible remaining regional variation in depreciation rates and technological progress that is not represented by any of the other terms will be regulated by the introduction of regional dummies in the LSDV (Least Squares Dummy Variable) model.

The second explanatory variable, $s_{k}$, is the rate of increase in physical capital stock. Since there exist no statistics about regional capitals stocks and we have no reliable way of approximating the rate of capital depreciation, we will use the 
regional ratio of real gross fixed capital formation to real GDP as a proxy for the net increase in capital stocks. Thus, we must assume a homogeneous structure of investments and a uniform depreciation rate for different types of physical capital across all regions. ${ }^{3}$ Because the investment rate is very volatile and because observations of regional investment during recent years are not available due to a recent restructuring of regional statistics, we will average them over the time intervals instead of the exact year of the cross section. The pattern of regional differences in investment rates has remained rather stable over the years, and this variable represents strong features of convergence between regions as the investment rate has constantly remained higher in poorer regions. ${ }^{4}$

The third explanatory variable is the rate of human capital accumulation, $s_{h}$. Following McCullum (1996, p. 63), this is proxied with the first difference in the fraction of individuals with educational qualifications in the upper secondary level. This variable replaces the variable of the fraction of the working age population currently enrolled in secondary school that was used by M-R-W. This way we avoid any simultaneity biases concerning this variable, since we apply the differences of existing human capital levels. That is, measures are based on the fraction of the population that attended (in the past) the upper secondary level. Furthermore, this variable has some elements of convergence between the advanced and more backward regions, since the educational level of the workforce, which has considerably increased in all regions, was found to have risen particularly in these economically less-favored areas.

Other explanatory variables considered important for regional growth (at least in a country with a Nordic type of economy) are included in vector $F$. In the basic model, this comprises only the structure of production, which is here measured by the share of primary production of GDP. This variable is justified, as clearly there is potential for differences across regional productivity, stemming from varying factor endowments of natural resources, climate, and location. To the extent that these differences are both statistically significant and correlated with typical rates and forms of investment in each province, the exclusion of these factors is inappropriate and produces misleading parameter estimates (see HoltzEakin 1993, p. $435^{5}$ ). Variance in the structure of production can be seen as an important factor that questions the assumption of homogeneity across regions, and by means of this independent variable we have kept this difference constant.

In the further-augmented model, we wished to achieve a better understanding of the relation between growth and the high level of taxation and the high degree of political monitoring, which are often found in the Nordic type of economy. As a result, we have augmented our basic model somewhat by including two additional explanatory variables in vector F, namely, public capital and

${ }^{3}$ Assuming a uniform depreciation rate on different forms of capital might be somewhat problematic, as it tends to overestimate the importance of investments on public infrastructure.

4The variable of the share of primary production included in the regressions should maintain constant regional differences inasmuch as poorer regions tend to be oriented to primary production and are therefore more capital intensive.

${ }^{5}$ In simplistic convergence equations, this variable is used to characterize the differences in the determinants of regional steady states. 
political climate. Following Temple (1999, p. 124), we can state that when this more informal variable enters a growth regression it is not always so clear whether it actually affects the long-run growth rate (as we should assume) or merely the steady-state level of output, or both. Disentangling the two is rarely possible, but this is not too devastating since a large effect on the steady-state level of output may be as important as a growth effect and just as relevant for policy.

Our variable of public capital or infrastructure capital is partially reflected in the overall investment level. Several authors, however, have emphasized the importance of infrastructure to productivity in a manner of threshold at the different levels of the community maturation (see Aschauer 1997). Therefore, we have included the variable of municipal expenditure in core public capital, that is, in community planning and financing, public works, real estate, and public order. We consider this mode of spending to be more important for economic growth versus expenditure of a more social nature, i.e., public health care, social welfare, education, and culture, although these two modes of spending are in practice highly correlated in Finland. ${ }^{6}$ The second factor considered important in determining the economic performance of a region is its political structure. In the Finnish multiparty system, it would be interesting to use measures of the stability of governing party coalitions or the effects of clear majorities in municipal councils as explanatory variables. Since these complicated measures do not exist in official statistics, we have used the proportion of left-wing councilors elected in municipal elections in 1972,1980,1988, and 1996 as a bellwether of the political climate. Voting in Finland is very much based on occupational factors and thus the proportion of left-wing voters is usually larger in more developed and urbanized areas. Nevertheless, we suppose that this division between left-wing and rightwing political parties reflects different attitudes regarding the share of the public sector in production, the level of taxation, and the general goodwill to private business activities. It is safe to assume that these political premises have important output and employment outcomes that are in an abnormal way determined outside the pure market-based decision-making process.

Finally, real GDP per capita, lagged one period, is used as a measure of initial productivity in all of the equations. It also measures the distance of regional output levels with respect to their steady state-levels, as described earlier. Thus, we can now omit the naive assumption that all regions share a common level of initial technology and a common steady state-level as well.

\section{ESTIMATION RESULTS}

\section{Panel Growth Regressions when Applying the Basic Model} written as

We begin with the M-R-W-type growth model-regression Equation 10

${ }^{6}$ Aschauer (1997) has maintained that in the United States the effect of core public capital on economic growth has been positive but that of social expenditure has been negative. 


$$
\begin{aligned}
y_{i, t}-y_{i, t-1}= & \theta_{1}\left(n_{i, t}+g+\delta\right)+\theta_{2} s_{k_{i, t-1}}+\theta_{3} s_{h_{i, t-1}}+\theta_{4} F_{i, t-1}+\lambda^{*} y_{i, t-1}+ \\
& \theta_{5} A_{0}+\zeta_{t}+\varepsilon_{i, t} .
\end{aligned}
$$

where $F_{i, t-1}=p p p_{i, t-1}$ and $\zeta_{t}$ represents the time-specific effect. All variables are described in Table 1.

Since we are using regional data on output per capita, thus allowing migration between regions, we expect the estimated values for $\theta_{1}$ to be positive. This violates the basic assumption derived from the Solow-Swan type model, which posits that the population growth per se is assumed to have a negative effect on the output per capita growth rate. The basic Solow-Swan model treats each region in isolation, but actually regions are open to flows of capital, labor, and, hence, human capital. To the extent that high-productivity regions attract investment and labor from low-productivity regions, the chain of causality is reversed and econometric inferences will be contaminated. In our analysis, the basic assumption of decreasing returns to labor inputs still holds, but immigration is expected to be concentrated in more prosperous regions to such an extent that the correlation between the two variables becomes positive. ${ }^{7}$

The estimated values for $\theta_{2}$ and $\theta_{3}$ (physical and human capital) are expected to be positive and those for $\lambda^{*}$ (initial level of productivity) to be negative. The effect of the level of primary production, $\mathrm{pp}$, on the observed growth of output and employment is expected to be negative. $\theta_{5}$ is the constant term, which represents the unobserved efficiency effects. Because the sequential Chow-test (1960) indicated the presence of a significant time-specific effect, $\zeta_{t}$, the model is estimated with a special intercept (not reported) for each of the time periods. Table 2 presents the estimation results for both growth of output, DY, and for change in employment, DE, across 11 Finnish continental provinces. ${ }^{8}$

\section{Basic Model with OLS Estimation}

The first column in Table 2 presents the OLS results for estimating the growth of regional output. We discern that all parameter estimates have the predicted sign and the $t$-statistic for all parameter estimates is statistically significant. Population growth and increase in physical and human capital are positively correlated with output growth. Respectively, the initial level of output and the share of primary production are negatively correlated with output growth. Note the large parameter estimate of the variable of initial output. Implied $\lambda$, the annual conditional convergence (in this model with structural differences between regions kept constant), is over 20 percent. ${ }^{9}$ This exceptionally high figure seems to 7This result can be derived from the Harris-Todaro (1970) type of model, where an increase in the number of high-wage jobs might increase the available workforce to the extent that unemployment in that sector (region) increases. This type of immigration is more likely to occur in the presence of a high level of unemployment benefits. This would seem plausible in the Finnish economy, where the cost of unemployment in the form of waiting for a high-wage job instead of accepting a low-wage job in one's native region is rather low. However, it is noteworthy that internal migration in Finland has been rather modest in comparison, for instance, to that of the U.S. 8The autonomous territory of the Åland Islands, highly dependent on tourism and shipping, has been excluded from the sample as too small and heterogeneous a region in relation to the other provinces in Finland.

9The coefficient -0.807 in the feasible generalized least squares (FGLS) model implies that, setting $r=8$ years, $\left(1-e^{-\lambda r}\right)$ in Equation 8 results in $\lambda=0.206$. 
result from migration and from the deep recession that hit the Finnish economy at the beginning of the 1990s. The real GDP per capita figures in the richest (the capital) region of Uusimaa were in 1996 below their 1988 levels and, by contrast, in most of the other regions the real GDP grew between the two periods. All in all, the model is fairly successful in its predictions concerning the determinants of standards of living and it has the anticipated econometric properties associated with such a model. ${ }^{10}$

\section{TABLE 2}

Basic M-R-W-Type Model for Growth of Output and Employment

\begin{tabular}{|c|c|c|c|c|c|c|}
\hline & (1) DY OLS & (2) DE OLS & (3) DY FGLS & (4) DE FGLS & (5) DY SUR & (6) DE SUR \\
\hline $\mathrm{n}$ & $\begin{array}{l}0.390-03 \\
(0.165)^{*}\end{array}$ & $\begin{array}{c}0.478-01 \\
(0.172)^{* *}\end{array}$ & $\begin{array}{l}0.423-03 \\
(0.098)^{* *}\end{array}$ & $\begin{array}{c}0.494-01 \\
(0.104)^{* *}\end{array}$ & $\begin{array}{c}0.436-03 \\
(0.159)^{* *}\end{array}$ & $\begin{array}{c}0.499-01 \\
(0.163)^{* *}\end{array}$ \\
\hline$s_{k}$ & $\begin{array}{c}0.277-02 \\
(0.160)^{*}\end{array}$ & $\begin{array}{l}-0.478 \\
(0.135)^{* *}\end{array}$ & $\begin{array}{c}0.173-02 \\
(0.099)^{*}\end{array}$ & $\begin{array}{l}-0.476 \\
(0.081)^{* *}\end{array}$ & $\begin{array}{c}0.323-02 \\
(0.155)^{*}\end{array}$ & $\begin{array}{l}-0.482 \\
(0.134)^{4 *}\end{array}$ \\
\hline$s_{h}$ & $\begin{array}{c}0.189-01 \\
(0.034)^{* *}\end{array}$ & $\begin{array}{l}1.038 \\
(0.413)^{* 4 *}\end{array}$ & $\begin{array}{c}0.166-01 \\
(0.022)^{* *}\end{array}$ & $\begin{array}{l}1.012 \\
(0.283)^{* *}\end{array}$ & $\begin{array}{c}0.191-01 \\
(0.034)^{* *}\end{array}$ & $\begin{array}{l}0.984 \\
(0.387)^{* *}\end{array}$ \\
\hline$x_{t-1}$ & $\begin{array}{l}-0.935 \\
(0.186)^{* *}\end{array}$ & $\begin{array}{l}-0.892 \\
(0.257)^{* *}\end{array}$ & $\begin{array}{l}-0.807 \\
(0.094)^{4 *}\end{array}$ & $\begin{array}{l}-0.835 \\
(0.126)^{* *}\end{array}$ & $\begin{array}{l}-1.046 \\
(0.156)^{* 4}\end{array}$ & $\begin{array}{l}-0.943 \\
(0.216)^{* *}\end{array}$ \\
\hline pp & $\begin{array}{l}-0.565-02 \\
(0.119)^{*}\end{array}$ & $\begin{array}{l}-0.145 \\
(0.076)^{*}\end{array}$ & $\begin{array}{l}-0.441-02 \\
(0.064)^{* 4}\end{array}$ & $\begin{array}{l}-0.141 \\
(0.043)^{* *}\end{array}$ & $\begin{array}{l}-0.620 \\
(0.109)^{* *}\end{array}$ & $\begin{array}{l}-0.150 \\
(0.075)^{*}\end{array}$ \\
\hline $\mathrm{A}_{0}$ & $\begin{array}{l}1.814 \\
(0.377)^{* *}\end{array}$ & $\begin{array}{l}59.120 \\
(20.898)^{\text {** }}\end{array}$ & $\begin{array}{l}1.594 \\
(0.179)^{* *}\end{array}$ & $\begin{array}{c}56.387 \\
(11.600)^{* *}\end{array}$ & $\begin{array}{l}2.038 \\
(0.318)^{* *}\end{array}$ & $\begin{array}{l}63.193 \\
(17.780)^{* *}\end{array}$ \\
\hline $\mathrm{R}^{2}$ & $82.5 \%$ & $77.1 \%$ & $91.7 \%(\mathrm{~B})$ & $81.5 \%(\mathrm{~B})$ & $82.2 \%$ & $77.0 \%$ \\
\hline SEE & $0.187-01$ & 1.772 & 1.051 & 1.096 & $0.168-01$ & 1.574 \\
\hline Mean & $0.576-01$ & 0.109 & $0.576-01$ & 0.109 & $0.576-01$ & 0.109 \\
\hline \multirow[t]{2}{*}{ F-ratio } & 20.353 & 14.570 & 47.958 & 19.146 & - & - \\
\hline & (7) DY IVE & (8) DE IVE & (9) DY LSDV & (10) DE LSDV & & \\
\hline $\bar{n}$ & $\begin{array}{c}0.336-03 \\
(0.184)^{*}\end{array}$ & $\begin{array}{l}0.155-01 \\
(0.233)\end{array}$ & $\begin{array}{l}0.174-03 \\
(0.379)\end{array}$ & $\begin{array}{l}0.352-01 \\
(0.301)\end{array}$ & & \\
\hline$s_{k}$ & $\begin{array}{l}0.210-02 \\
(0.181)\end{array}$ & $\begin{array}{l}-0.419 \\
(0.156)^{* *}\end{array}$ & $\begin{array}{l}0.069-02 \\
(0.282)\end{array}$ & $\begin{array}{l}-0.843 \\
(0.238)^{* *}\end{array}$ & & \\
\hline$s_{h}$ & $\begin{array}{c}0.178-01 \\
(0.034)^{* *}\end{array}$ & $\begin{array}{l}1.921 \\
(0.585)^{* *}\end{array}$ & $\begin{array}{c}0.172-01 \\
(0.044)^{* *}\end{array}$ & $\begin{array}{c}0.714 \\
(0.409) *\end{array}$ & & \\
\hline$x_{t-1}$ & $\begin{array}{l}-0.766 \\
(0.267)^{* *}\end{array}$ & $\begin{array}{l}-0.170 \\
(0.404)\end{array}$ & $\begin{array}{l}-1.216 \\
(0.224)^{* *}\end{array}$ & $\begin{array}{l}-1.303 \\
(0.311)^{* *}\end{array}$ & & \\
\hline pp & $-0.484-02$ & $\begin{array}{l}-0.079 \\
(0.090)\end{array}$ & $\begin{array}{l}-0.312-02 \\
(0.247)\end{array}$ & $\begin{array}{l}-0.047 \\
(0.194)\end{array}$ & & \\
\hline $\mathrm{A}_{0}$ & $\begin{array}{l}1.487 \\
(0.533)^{* 4}\end{array}$ & $\begin{array}{c}0.014 \\
(32.812)\end{array}$ & $\begin{array}{l}2.449 \\
(0.474)^{* *}\end{array}$ & $\begin{array}{l}98.813 \\
(21.099)^{* *}\end{array}$ & & \\
\hline $\mathrm{R}^{2}$ & - & - & $90.3 \%$ & $91.0 \%$ & & \\
\hline SEE & $0.194-01$ & 2.026 & $0.178-01$ & 1.412 & & \\
\hline Mean & $0.576-01$ & 0.109 & $0.576-01$ & 0.109 & & \\
\hline F-ratio & - & - & 9.274 & 10.167 & & \\
\hline
\end{tabular}

Notes: Standard errors are shown in parenthesis. Standard errors in all cells have the same exponent as estimated parameters have. All variables are defined in the text and in Table $1 . * / *=$ significant at the $5 / 1 \%$ level. $x_{t-1}$ presents initial level of output, $y_{t-1}$, in growth equation, and initial level of employment, $e_{t-1}$, in employment equation, respectively. (B) refers to Buse (1973) $R^{2}$.

10The explanatory power of the model is highly satisfactory. The Jarque-Bera (1980) test indicates normality in the OLS residuals and Ramsey's (1969) RESET test and other diagnostic tests are favorable to the model specification. On the other hand, the Durbin-Watson h-statistics (Durbin 1970) imply serial correlation in our data set. Furthermore, the Breusch and Pagan (1979) and Godfrey (1978) test for unknown form of heteroskedasticity, B$\mathrm{P}-\mathrm{G}=13.672$, is statistically significant as $\chi_{0.05}^{6}=12.592$, indicating the possibility of parameter inconstancy across regions. As expected, the so-called condition index indicates strong multicollinearity among regressors (see Belsey, Kuh, and Welsch 1980), nevertheless. 
When we focus our attention to the employment model in the second column of Table 2, we find that the statistical fit of the model is almost identical. All parameter estimates are highly significant and the explanatory power of the model is strong. Note that partial correlation between the accumulation of physical capital and the dependent variable is now negative. This implies that physical capital and labor are acting as substitutes for one another or, at least, that the development of employment has been less favorable in less-advanced areas, where the investment ratio has been higher. Also in this model we detect the presence of heteroskedasticity in errors, B-P-G $=10.801$, now significant at the $10 \%$ level. As discussed earlier, we have a strong reason to believe this is due to spatial interdependency between our units of observation, e.g., cross-sectional heteroskedasticity. Therefore, we will next apply alternative estimation methods intended to improve the efficiency of estimation in comparison to the traditional OLS method.

\section{Basic Model and Cross-Sectional Heteroskedasticity}

Since most analysts are not willing to accept the assumption of spherical errors for panel data models, we will next use a feasible generalized least squares (FGLS) procedure for a cross-sectionally heteroskedastic and time-wise autoregressive model. ${ }^{11}$

Columns 3 and 4 in Table 2 present the same models estimated now with panel-corrected standard errors. It is easy to notice that the parameter estimates are altered only modestly, while all the standard errors of parameter estimates are considerably reduced. This result would seem to correspond closely with the results of Baltagi's (1981) Monte Carlo study of alternative testing and estimation procedures, using a random effects panel model. With our growth models, we can notice how the significance of estimates considerably increases when compared to the OLS estimates. Similarly, the explanatory power of the models improves, though SEE is now larger in the DY model. Thus, we can conclude that the FGLS procedure provides a high degree of efficiency for our estimation even though the OLS estimates are consistent for the purpose of qualitative applied research.

For the sake of comparison, the same models were also estimated within a system of seemingly unrelated regressions, SUR, also called multivariate regressions. The SUR method allows for regional random effects that are correlated over time, that is, over the single panel regression equations. It is realistic to expect a correlation between errors of output and employment equations and the SUR method, by exploiting this correlation, allows for a reduction in standard errors associated with the individual coefficient estimates. The results of these estimations are presented in the fifth and sixth columns in Table 2. The same conclusions apply about the significance of the parameters, that is, parameter estimates are not

${ }^{11}$ This way, at the first stage we neglect the possibility of specific characteristics of cross-sectional units and assume that regression disturbances are mutually independent. The estimation method is described in Parks (1967) and further discussed in Kmenta (1986, pp. 618-622). Following the Monte Carlo simulations of Beck and Katz (1995), which strongly favor correcting serially correlated errors with a common autoregressive parameter $\rho$, we will apply a method that will assume the same autoregressive coefficient for all cross sections. 
severely altered, although the effects of the convergence factors, $x_{t-1}$ and $p p$, are now emphasized. The standard errors of individual coefficient estimates are reduced when compared to their OLS equivalents, however not as significantly as when using the FGLS procedure. Thus, it was proven that our FGLS procedure emerges as the most effective way of dealing with cross-sectional heteroskedasticity found in our panel data.

\section{The Basic Model and the Simultaneity Bias Problem}

We next turn out attention to the other significant problem, namely, the possible inconsistency caused by the endogeneity of right-hand regressors. The method of instrumental variable (IV) estimation was developed to handle these kinds of endogenous regressors. Moreover, it also will help to overcome the potential biases caused by measurement errors in the data. We shall use the most commonly accepted approach, where first-differenced lags of the dependent variables are employed as instruments under the assumption of white noise errors. Unfortunately, the exogeneity of even the differentiated higher lags in panels is not always clear, since there may exist long delays in the effects of some of the variables. Following Arellano and Bond's (1991) application to the employment equation, we shall test the validity of the instrumental variables (i.e., test the lack of this serial correlation) by applying Sargan's (1980) specification test.

We shall then eliminate potential endogeneity by applying the IV estimation method using differenced first and second lags of all of the independent variables as instruments. ${ }^{12}$ We found in the IV estimations presented in the seventh and eighth columns of Table 2 that the previous findings of significance of the variables in the growth regression were not altered compared with those obtained via OLS estimation. Only the parameter estimate for physical capital, $s_{\mathrm{k}}$, is no longer significantly determined, possibly due to its simultaneity with the structure of production. The absolute values of these structural form estimates are slightly reduced, as they undoubtedly should when instruments are used, but the SEE remains small. First-stage recursive form estimates (not reported) suggest that the instruments are only weakly correlated with the right-hand-side variables. But in the light of conventional direct type tests on residuals, there appears to be no significant serial correlation and Sargan's (1980) specification test does not reject our IV specification at the $5 \%$ level. We can conclude that IV modeling brings some additional efficiency to our estimation, but the previous results from the growth model do not appear to be seriously affected by any simultaneity bias. By contrast, in the employment equation the IV specification is strongly rejected and the results of this estimation cannot be considered adequate.

${ }^{12}$ We also considered the use of the potentially more efficient Generalized Method of Moments (GMM) estimator of Hansen (1992) instead of the simpler IV estimator. Since the reduced form estimates with this method were not severely different from those of the traditional IV method, we did not consider this alternative relevant. 


\section{Basic Model under Region-Specific Effects}

Finally, we will revise out the assumption that the regression disturbances of cross-sectional units are mutually independent and assume that the error terms are correlated with some or all of the explanatory variables. To correct this potential endogeneity-in-error-term problem, we shall experiment with a fixed effect model. This is because, according to the theory, the correlation between the exogenous variables and the individual effects of the cross sections must conceptualize as a parameter (see Islam 1995), unlike in the error component or the random effect model, where this correlation is assumed to be a normally distributed random variable. To overcome this type of endogeneity problem, we shall proceed with the assumption that the unobserved effect of the initial level of technology, the most frequently expressed reason for endogeneity, can be treated as a fixed effect. The same assumption is applied to the effect of any other possibly omitted variable that is similarly persistent over time and correlated with any of the explanatory variables. According to this assumption, the time dimension of panel data can be used to eliminate its influence on the growth regressions by applying the least squares dummy variables (LSDV) model, where each cross-sectional unit in the panel data is characterized by its own special intercept.

LSDV estimations in the next columns of Table 2 were initiated by testing the significance of the individual dummy variable on each of the regions separately. None of the dummies was found significant, but when a dummy was set on the capital region of Uusimaa, the population growth variable was no longer determined as significantly positive. This reflects the fact that the capital region has had some factor(s) outside the M-R-W model (capital status, history, political preferences, metropolitan externalities, etc.) that partially explain its attractiveness to migrants. Accordingly, when a dummy was set on the province of Häme, the parameter of the production structure was no longer significant. This may reflect the fact that the Häme region, despite its high rate of industrialization and relatively low level of primary production, has exhibited rather feeble growth rates during recent decades. This tendency is probably to some extent due to its industrial structure, which has been heavily based on traditional paper and lumber industries and less oriented to machinery, equipment, and electronics, all of which have been the topmost growth sectors of the Finnish manufacturing industry during previous decades.

These above-mentioned observations remind us of the fact that the regional dummy variables will also reflect many other factors besides the theoretically suppositious (unobserved) variable of the initial level of technology alone. As Kmenta (1986, p. 633) remarks, the reasoning underlying the LSDV model is that in specifying the regression model we have failed to include relevant explanatory variables that do not change over time, with the inclusion of dummy variables only serving as a cover-up for our ignorance. Furthermore, it must be noted that the inclusion of regional dummies causes the degrees of freedom in our models to drop to a dangerously low level. Nevertheless, we accept these results as the best 
available approximations of the true relationships of variables ascertainable by the means of the LSDV model and present these estimates in the ninth and tenth columns in Table 2. The results repeat the findings of individual dummies in the sense that population growth, investment in physical capital, and the structure of production are no longer statistically significant determinants of growth, though the signs of these variables remain the same. Characteristic of these dummy variable models, the $R^{2}$ values (also when adjusted to degrees of freedom) rise and SEE values remain low, but, as noticed, this does not necessarily reflect the significant correction of the endogeneity-in-error-term bias. Rather, the LSDV model more effectively exposes variables relevant to growth that are shared by all regions, and simultaneously hides the fact that the growth process is severely affected by the structure of the production as well as by migration.

\section{The Model Further Augmented}

Table 3 reports the results of the further augmented version of the SolowSwan model. Its corresponding regression is again derived from Equation 11. Vector $F$ is now interpreted to include not only the structure of production (i.e., the share of primary production, pp), but also proxies for investments on public infrastructure, pc, and the composition (left-wing bias) of political climate, ps. We expect the estimated coefficient for pc to be positive. The estimate for $\mathrm{ps}$ is expected to be negative, because in the entirely market-based neoclassical framework we must assume that a left-wing oriented policy leads to a larger share of public production and increases the level of social income transfers. These may well improve the actual well-being of the citizenry, ${ }_{1}^{13}$ but retard observed growth in the market sector unless the political decision maker succeeds in optimizing the savings rate in the economy. In a regional neoclassical model, we may interpret this presupposed development in the public sector as an example of the so-called Baumol's Law (after Baumol 1967). It tells us that a sector such as the public sector, which generates products with relatively income elastic but price inelastic demand, inevitably grows in terms of its relative share as the economy expands. Because the productivity in the public sector is considered relatively constant, this development should lead to deteriorating economic growth in the economy. Apart from controlling the determinants of the steady state across regions and different technologies, it is important to take account of the different levels of the regional productive infrastructure and different regional political preferences. Both of these additional factors are assumed to affect the rate of savings and different types of capital formation, as well as the rate of technological progress.

\section{Augmented Model with OLS Estimation}

The first two columns in Table 3 present OLS-estimated coefficients of the DY and DE model. They are again statistically significant and have the expected signs. Concerning the new additional variables, we found that a larger expenditure

${ }^{13}$ This is the case if we interpret the households' felicity function to relate the flow of utility not only to the quantity of consumption per person, but also to the quantity of services provided by the public sector. 
of public capital, pc, is positively correlated with the output growth rate, and a larger share of left-wing councilors, ps, has a negative correlation, as was anticipated. It is somewhat daring to interpret this negative coefficient of ps to confirm that a more left-wing oriented economic policy straightforwardly means less growth in an economy. More likely, we are again dealing with the simultaneity problem (see Mankiw 1995, pp. 303-304), as the causal channel between these two variables may in fact be inverse. In the Finnish regional economy, it is found that when the differences in the structure of production are held constant, the share of left-wing voters is relatively larger in the less-favored regions of Eastern and Northern Finland. This fact is probably related to the stronger demand for income equality between these constituencies and the more prosperous regions through increased income transfers. Moreover, as mentioned before, the correlation between the share of left-wing voters and the degree of urbanization is positive and thus also related to other important factors of convergence between regions.

When OLS results of the DY model as a whole are compared with the ones presented in Table 2, we notice that the parameter estimates of all variables included in the previous model are now slightly smaller, which is to be expected with these new additional variables. Correspondingly, the value of the constant term (reflecting the remaining exogenous technological factors) is modestly reduced.

In the DE model, on the other hand, the value of these new variables is limited. Parameter estimates for human capital and primary production in this model are no longer significant. We may conclude that, despite the fact that the basic model performed extremely well, adding public capital and political structure to the model improves at least the DY model's performance markedly. For instance, the standardized coefficient of determination rises now to $86.4 \%$ in the DY model and also its SEE is reduced. The usual tests do not indicate significant heteroskedasticity or autocorrelation in either of these augmented models. Nevertheless, we again estimate them by means of FGLS, SUR, IV, and LSDV procedures in order to test the increased estimation efficiency gained by using these methods in a panel regression.

\section{Augmented Model and the Statistical Problems}

Concerning the problem of cross-sectional heteroskedasticity, the FGLS estimates presented in the third and fourth column in Table 3 show again how the parameter estimates remain fairly stable, although their standard errors are considerably reduced. This implies a need to panel-correct the standard errors in this further augmented model as well. Instead, the SUR estimates, presented in the next two columns, are in their three digit levels almost identical to their OLS equivalents, though standard errors of estimates are reduced. This denotes that for these models the correlation between the errors of the two models is rather limited. We may conclude that also in these models the FGLS method leads to a significant improvement of efficiency of estimation, even though the OLS estimates are more than adequately congruent for the basis of policy analysis. 
TABLE 3

Further-Augmented M-R-W Model for Growth of Output and Employment

\begin{tabular}{|c|c|c|c|c|c|c|}
\hline & (1) DY OLS & (2) DE OLS & (3) DY FGLS & (4) DE FGLS & (5) DY SUR & (6) DE SUR \\
\hline n & $\begin{array}{l}0.241-03 \\
(0.136)^{*}\end{array}$ & $\begin{array}{c}0.353-01 \\
(0.114)^{* *}\end{array}$ & $\begin{array}{c}0.156-03 \\
(0.092)^{*}\end{array}$ & $\begin{array}{c}0.405-01 \\
(0.055)^{* *}\end{array}$ & $\begin{array}{c}0.241-03 \\
(0.116)^{*}\end{array}$ & $\begin{array}{c}0.353-01 \\
(0.097)^{* *}\end{array}$ \\
\hline$s_{k}$ & $\begin{array}{c}0.417-02 \\
(0.144)^{* *}\end{array}$ & $\begin{array}{l}-0.308 \\
(0.104)^{* *}\end{array}$ & $\begin{array}{c}0.320-02 \\
(0.124)^{* *}\end{array}$ & $\begin{array}{l}-0.293 \\
(0.061)^{* *}\end{array}$ & $\begin{array}{c}0.418-02 \\
(0.123)^{* *}\end{array}$ & $\begin{array}{l}-0.308 \\
(0.089)^{* *}\end{array}$ \\
\hline$s_{h}$ & $\begin{array}{c}0.120-01 \\
(0.034)^{* *}\end{array}$ & $\begin{array}{c}0.416 \\
(0.287)\end{array}$ & $\begin{array}{c}0.999-02 \\
(0.267)^{* *}\end{array}$ & $\begin{array}{c}0.275 \\
(0.186)\end{array}$ & $\begin{array}{c}0.120-01 \\
(0.029)^{* *}\end{array}$ & $\begin{array}{c}0.416 \\
(0.245)\end{array}$ \\
\hline$x_{t-1}$ & $\begin{array}{l}-0.824 \\
(0.150)^{* *}\end{array}$ & $\begin{array}{l}-0.861 \\
(0.168)^{* *}\end{array}$ & $\begin{array}{l}-0.728 \\
(0.128)^{* *}\end{array}$ & $\begin{array}{l}-0.899 \\
(0.113)^{* *}\end{array}$ & $\begin{array}{l}-0.825 \\
(0.128)^{* *}\end{array}$ & $\begin{array}{l}-0.861 \\
(0.143)^{* *}\end{array}$ \\
\hline pp & $\begin{array}{l}-0.426-02 \\
(0.104)^{* *}\end{array}$ & $\begin{array}{l}-0.669-01 \\
(0.559)\end{array}$ & $\begin{array}{l}-0.317-02 \\
(0.083)^{* *}\end{array}$ & $\begin{array}{l}-0.167-01 \\
(0.328)\end{array}$ & $\begin{array}{l}-0.427-02 \\
(0.088)^{* *}\end{array}$ & $\begin{array}{l}-0.669-01 \\
(0.476)\end{array}$ \\
\hline pc & $\begin{array}{c}0.157-04 \\
(0.040)^{* *}\end{array}$ & $\begin{array}{c}0.167-02 \\
(0.030)^{* * *}\end{array}$ & $\begin{array}{c}0.159-04 \\
(0.030)^{* *}\end{array}$ & $\begin{array}{c}0.200^{-02} \\
(0.019)^{* *}\end{array}$ & $\begin{array}{c}0.157-04 \\
(0.034)^{* *}\end{array}$ & $\begin{array}{c}0.167-02 \\
(0.026)^{* *}\end{array}$ \\
\hline ps & $\begin{array}{l}-0.923-03 \\
(0.467)^{*}\end{array}$ & $\begin{array}{l}-0.134 \\
(0.036) * *\end{array}$ & $\begin{array}{l}-0.958-03 \\
(0.357)^{* *}\end{array}$ & $\begin{array}{l}-0.177 \\
(0.022)\end{array}$ & $\begin{array}{l}-0.922-03 \\
(0.398)^{* *}\end{array}$ & $\begin{array}{l}-0.134 \\
(0.030)^{* *}\end{array}$ \\
\hline$A_{0}$ & $\begin{array}{l}1.637 \\
(0.303)^{* *}\end{array}$ & $\begin{array}{c}63.556 \\
(14.200)^{* *}\end{array}$ & $\begin{array}{c}1.472 \\
(0.246)^{* *}\end{array}$ & $\begin{array}{l}67.873 \\
(9.669)^{* * *}\end{array}$ & $\begin{array}{l}1.641 \\
(0.258)^{* *}\end{array}$ & $\begin{array}{l}63.601 \\
(12.110)^{* *}\end{array}$ \\
\hline $\mathrm{R}^{2}$ & $89.8 \%$ & $91.5 \%$ & $82.8 \%(\mathrm{~B})$ & $96.1 \%(\mathrm{~B})$ & $89.8 \%$ & $91.5 \%$ \\
\hline SEE & $0.149-01$ & 1.124 & 1.120 & 1.139 & $0.127-01$ & 0.959 \\
\hline Mean & $0.576-01$ & 0.109 & $0.576-01$ & 0.109 & $0.576-01$ & 0.109 \\
\hline \multirow[t]{2}{*}{ F-ratio } & 26.368 & 32.215 & 14.423 & 73.096 & - & - \\
\hline & (7) DY IV & (8) DE IV & (9) DY LSDV & (10) DE LSDV & & \\
\hline n & $\begin{array}{l}0.203-03 \\
(0.146)\end{array}$ & $\begin{array}{l}0.230-01 \\
(0.129)^{*}\end{array}$ & $\begin{array}{l}0.085-03 \\
(0.323)\end{array}$ & $\begin{array}{l}0.253-01 \\
(0.251)\end{array}$ & & \\
\hline$s_{k}$ & $\begin{array}{c}0.383-02 \\
(0.152)^{* *}\end{array}$ & $\begin{array}{l}-0.282 \\
(0.110)^{* *}\end{array}$ & $\begin{array}{l}0.332-02 \\
(0.258)\end{array}$ & $\begin{array}{l}-0.622 \\
(0.202)^{* *}\end{array}$ & & \\
\hline$s_{h}$ & $\begin{array}{c}0.103-01 \\
(0.038)^{* *}\end{array}$ & $\begin{array}{c}0.752 \\
(0.332)^{*}\end{array}$ & $\begin{array}{l}0.102-01 \\
(0.043)^{*}\end{array}$ & $\begin{array}{c}0.378 \\
(0.355)\end{array}$ & & \\
\hline$x_{t-1}$ & $\begin{array}{l}-0.693 \\
(0.193)^{* *}\end{array}$ & $\begin{array}{l}-0.617 \\
(0.209)^{* *}\end{array}$ & $\begin{array}{l}-1.143 \\
(0.209)^{* *}\end{array}$ & $\begin{array}{l}-0.861 \\
(0.285)^{* * *}\end{array}$ & & \\
\hline pp & $\begin{array}{l}-0.357-02 \\
(0.122)^{* *}\end{array}$ & $\begin{array}{l}-0.393-01 \\
(0.593)\end{array}$ & $\begin{array}{l}-0.248-02 \\
(0.206)\end{array}$ & $\begin{array}{c}-0.082 \\
(0.160)\end{array}$ & & \\
\hline pc & $\begin{array}{c}0.168-04 \\
(0.041)^{* *}\end{array}$ & $\begin{array}{c}0.170-02 \\
(0.031)^{* *}\end{array}$ & $\begin{array}{c}0.159-04 \\
(0.054)^{* *}\end{array}$ & $\begin{array}{c}0.128-02 \\
(0.043)^{* *}\end{array}$ & & \\
\hline ps & $\begin{array}{l}-0.910-03 \\
(0.479)^{*}\end{array}$ & $\begin{array}{l}-0.130 \\
(0.037)^{*}\end{array}$ & $\begin{array}{l}-0.667-02 \\
(0.303)^{*}\end{array}$ & $\begin{array}{l}0.009-01 \\
(4.024)\end{array}$ & & \\
\hline$A_{0}$ & $\begin{array}{l}1.389 \\
(0.384)^{* *}\end{array}$ & $\begin{array}{c}42.443 \\
(17.543)^{*}\end{array}$ & $\begin{array}{l}2.577 \\
(0.506)^{* *}\end{array}$ & $\begin{array}{c}66.378 \\
(23.804)^{* *}\end{array}$ & & \\
\hline $\mathrm{R}^{2}$ & - & - & $94.3 \%$ & $95.0 \%$ & & \\
\hline SEE & $0.152-01$ & 1.159 & $0.146-01$ & 1.126 & & \\
\hline Mean & $0.576-01$ & 0.109 & $0.576-01$ & 0.109 & & \\
\hline F-ratio & - & - & 12.845 & 14.823 & & \\
\hline
\end{tabular}

Notes: Standard errors are shown in parenthesis. Standard errors in all cells have the same exponent as estimated parameters have. All variables are defined in the text and in Table $1 .^{*} / * \|$ significant at the $5 / 1 \%$ level. $x_{t-1}$ presents initial level of output, $y_{t-1}$, in growth equation, and initial level of employment, $e_{t-1}$, in employment equation, respectively. (B) refers to Buse (1973) $R^{2}$.

Moving on to the simultaneity problem and IV estimates, we found that the models function again very well, i.e., results resemble those of OLS estimation and Sargan's (1980) specification test does not reject the specification at the $10 \%$ level in the growth equation. By contrast, in the employment equation the specification is strongly rejected despite significant parameter estimates. By and large, the augmented models appear not to be contaminated by the significant simultaneity problem. 
The results of the LSDV estimations that are made according to the assumption of region-specific effects resemble those achieved with the basic model. This can be noticed when compared with the results presented in Table 2. Coefficients on population growth, investments in physical capital, and the share of primary production are imprecisely determined, but the additional variables of public capital and political preferences appear significant for GDP growth. In the employment equation, the same caution with regard to the importance of the independent variables must be practiced as before. However, the region-specific factors appear not to count for more than what had already been noticed with regard to the basic (nonaugmented) formulations.

All in all, we can conclude how the results repeat the findings of the basic model and emphasize that the two additional variables, public capital and political factors, have statistically a significant influence on the observed regional growth rates. Our conclusion does imply that the further augmentation of the M-R-W model notably increases the performance of the model in explaining the majority of cross-regional variation in GDP growth in Finland without losing any theoretical rigor or causing significant statistical quandaries.

\section{SENSITIVITY ANALYSIS OF THE RESULTS}

\section{Sample Sensitivity}

There is little point in carrying out a cross section regression unless one checks sensitivity in relation to the choice of sample. The estimated results presented above could in fact be an illusion if the results are heavily influenced by a small group of sample units or important outliers. The most obvious approach to test sample sensitivity in regional panel data is to set dummy variables for individual regions. This approach was discussed earlier (in section 4, Basic Model under Region-Specific Effects) where only Uusimaa was found to present significant abnormality with respect to the other provinces, probably only due to its irregular population growth rate. In order to test further this potential problem of sample sensitivity, we decided to use a more precise single-case diagnostic. For this purpose, we applied Cook's (1977) distance measure and the studentized residuals, which are usually easy to implement and interpret. We were able to detect only one outlier in our basic version of the DY model, as well as one or two observations with large leverages in other models. In all of these cases it was easy, with the help of graphical analysis, to identify these possible outliers and characterize why they might be unusual. They all represented the capital province of Uusimaa in the first or second time period of the sample. The capital region has had an unusually rapid growth of output and employment during these periods, possibly due to metropolitan effects and politically characterized agglomeration factors that have concentrated most of the head-office and R\&D activities in this region. The capital region in Finland is often characterized as somehow unrepresentative and this anomalousity could naturally be treated with a dummy variable when running growth regressions. This option was tested in accordance with our LSDV 
modeling. However, in order to keep our results general enough, this easy technique to increase the $R^{2}$ power of the model was in general not preferred. In conclusion, based on our results, we will proceed with the assumption that the usual outlier diagnostics do not imply a serious outlier problem within our sample.

On the other hand, one must recognize that these single-case diagnostics may fail to pick up a larger group of outliers or leverage points (the "masking" effect) or wrongly identify some observations as unrepresentative, due to the presence of other observations (the "swamping" effect, Temple 1998). Although we do not have theoretical grounds for such a grouping in the Finnish regional economy, we explored the data with robust regression methods, resistant to outliers. The methods of Least Absolute Errors and Jackknife estimation were applied. None of these re-estimations provided results with considerably different coefficient estimates. The signs, significance, and values of the coefficients remained very similar and they shall not be reported in this article. ${ }^{14}$

The result gives reason to believe that the previous findings are reasonably robust with respect to the exact choice of sample. Discarding observations that are somehow unrepresentative (that is, those of the capital region) would apparently not have a large influence on the results. Furthermore, excluding these observations would in fact violate the theoretical rigor of the analysis, as it is often the case that regional dummies add substantially to a growth regression's explanatory power (but these dummies reflect only the fact that there is spatial correlation in the data set-see Equation 10). The fact that disturbances in cross-region growth regressions are not as independently distributed as they should be is probably the result of the differences in the initial efficiency of the examined regions. In this respect, one can conclude that the atypical growth experience of the capital region vis-à-vis the other Finnish regions is more likely to reward any further study of the regional dynamics in the Finnish economy.

\section{Model Sensitivity}

As known, economic theory in general does not generate a complete specification of which variables should be included in growth regressions. Another significant problem of empirical growth analysis is related to measurement errors, that is, we must use rather crude proxy variables (e.g., for measurement of human capital). Given that over 50 variables have been found significantly correlated with economic growth in at least one regression, it is rather easy to build an informal growth model with significant parameter estimates and high $R^{2}$ value (Levine and Renelt 1992, p. 942). Thus, many candidate regressions have equal theoretical status, but the estimated coefficients of the variables may depend significantly on the conditioning set of information, i.e., the results may be extremely susceptible to small alterations in the set of additional explanatory variables.

To test the significance of the results presented above, we shall use a variant of Leamer's (1983) and Levine and Renelt's (1992) extreme-bounds analysis, EBA. Our EBA uses equations of the form

${ }^{14}$ These results are available from the author upon request. 


$$
Y=\beta_{i} I+\beta_{z} Z+u,
$$

where $Y$ is either real per capita GDP growth or the change in employment, $I$ is a set of variables included in our further augmented regressions as presented in Table $3, \mathrm{Z}$ is a subset of variables chosen from a pool of variables identified by past studies as potentially important explanatory variables of regional growth, and $u$ is the error term. Our EBA involves varying the subset of Z-variables included in the OLS regressions to find the highest and lowest values (extreme bounds) for the coefficients of the I-variables. If $\beta_{\mathrm{i}}$ remains significant at the $5 \%$ significance level and has the same sign at the extreme bounds as in the base model, then we can consider the result as robust. If the coefficient does not remain significant or changes sign, we can consider the result as fragile.

We have previously observed collinearity among our explanatory variables and one possible objection to this EBA is that it increases the multicollinearity of the model. Thus, it exaggerates the extreme bounds of the coefficients and may falsely categorize variables as fragile. However, this phenomenon in fact reflects a weak-data problem, which only indicates that there is not enough independent variation in that variable to explain differences in growth.

The set $Z$ consists of seven condition variables that have been identified by past studies as potentially important explanatory variables of regional growth. The research method of our EBA is such that previous estimations are re-run, including all these condition variables in the model, one at the time in random order, resulting in the total number of independent variables ranging from eight to fifteen. Then we identify the highest and lowest values of the coefficient on the variable of interest in the augmented model. Note that augmentation of the basic model already represented a kind of test of robustness for the five variables present in the basic model.

The first of the seven Z-variables (listed also in Table 1) is the growth of the proportion of the work force with a tertiary education. Several studies have emphasized the importance of university-level education for economic growth (see, for instance, Chatterji 1998). The highest education is considered especially important for R\&D activities and their practical applications, which are seen as key factors in technological development, especially in models of endogenous growth. Second, variables that proxy the degree to which the regions have been interlinked with national transportation networks, i.e., in highways and railways, are used as a measure of spatial factors of growth. A high level of accessibility via highways and/or railways is assumed vital for several kinds of economic activity involving transportation of people and goods between market areas. Reduced transportation and time costs are assumed to increase the interregional and intraregional spatial efficiency and bestow a competitive edge upon those regions more easily accessible by means of transportation. Next, the municipal expenditure in the social sector is applied as a gauge of public capital not directly intended to augment economic efficiency. One might expect certain portions of other forms of public capital to be important especially for employment growth. For instance, 
a large portion of expenditure employed in education and health care is presumed to amend the employment proficiency and well-being of the citizens of the region in question. As a result, it seems reasonable to take into account the means by which public capital is financed, i.e., public debt and taxes. These financial variables-municipal debt per citizen and local income tax rate-are tested for their effect (presumably negative) on both output and employment growth. Finally, we also have tested the often-proposed agglomeration effects with the variable of population density found in each region. ${ }^{15}$ The results of EBA analysis for output growth model are presented in Table $4 a$.

\section{TABLE 4a}

Sensitivity Results for Variables in Augmented M-R-W Model

Dependent Variable: Growth Rate of Real Per Capita Regional GDP, 1973-1996

\begin{tabular}{|c|c|c|c|c|c|c|}
\hline I-variable & Coefficient & $\begin{array}{l}\text { Standard } \\
\text { Error }\end{array}$ & t-statistic & $\mathrm{R}^{2}$ & $\begin{array}{c}\mathrm{Z}- \\
\text { variables }\end{array}$ & $\begin{array}{c}\text { Robust/ } \\
\text { Fragile }\end{array}$ \\
\hline $\mathrm{n}$ & $\begin{array}{l}\text { h: } 0.000241 \\
\text { b: } 0.000241 \\
\text { l: } 0.001213\end{array}$ & $\begin{array}{l}0.000136 \\
0.000136 \\
0.000158\end{array}$ & $\begin{array}{l}1.77 \\
1.77 \\
0.77\end{array}$ & $\begin{array}{l}0.90 \\
0.90 \\
0.91\end{array}$ & $1-2$ & fragile \\
\hline$\overline{s_{k}}$ & $\begin{array}{l}\text { h: } 0.004405 \\
\text { b: } 0.004174 \\
\text { l: } 0.003559\end{array}$ & $\begin{array}{l}0.002344 \\
0.001439 \\
0.001721\end{array}$ & $\begin{array}{l}1.88 \\
2.90 \\
2.07\end{array}$ & $\begin{array}{l}0.91 \\
0.90 \\
0.91\end{array}$ & $\begin{array}{l}1-7 \\
1-3\end{array}$ & robust \\
\hline$\overline{s_{h}}$ & $\begin{array}{l}\text { h: } 0.013400 \\
\text { b: } 0.012027 \\
\text { l: } 0.011470\end{array}$ & $\begin{array}{l}0.003399 \\
0.003352 \\
0.004285\end{array}$ & $\begin{array}{l}3.94 \\
3.59 \\
2.68\end{array}$ & $\begin{array}{l}0.91 \\
0.90 \\
0.91\end{array}$ & $\begin{array}{l}1 \\
1-5\end{array}$ & robust \\
\hline$\overline{y_{t-1}}$ & $\begin{array}{l}\text { h: }-0.759903 \\
\text { b: }-0.823692 \\
\text { l: }-0.823692\end{array}$ & $\begin{array}{l}0.176306 \\
0.149838 \\
0.149838\end{array}$ & $\begin{array}{l}-4.31 \\
-5.50 \\
-5.50\end{array}$ & $\begin{array}{l}0.91 \\
0.90 \\
0.90\end{array}$ & $1-5$ & robust \\
\hline$\overline{\mathrm{pP}}$ & $\begin{array}{l}\text { h: }-0.003288 \\
\text { b: }-0.004262 \\
\text { l: }-0.004262\end{array}$ & $\begin{array}{l}0.001254 \\
0.001036 \\
0.001036\end{array}$ & $\begin{array}{l}-2.62 \\
-4.11 \\
-4.11\end{array}$ & $\begin{array}{l}0.91 \\
0.90 \\
0.90\end{array}$ & $1-5$ & robust \\
\hline$\overline{\mathrm{pc}}$ & $\begin{array}{l}\text { h: } 0.000030 \\
\text { b: } 0.000016 \\
\text { l: } 0.000016\end{array}$ & $\begin{array}{l}0.000011 \\
0.000004 \\
0.000004\end{array}$ & $\begin{array}{l}2.80 \\
3.93 \\
3.93\end{array}$ & $\begin{array}{l}0.91 \\
0.90 \\
0.90\end{array}$ & $1-5$ & robust \\
\hline$\overline{\mathrm{ps}}$ & $\begin{array}{l}\text { h: }-0.000922 \\
\text { b: }-0.000922 \\
\text { l: }-0.001532\end{array}$ & $\begin{array}{l}0.000467 \\
0.000467 \\
0.000667\end{array}$ & $\begin{array}{l}-1.98 \\
-1.98 \\
-2.30\end{array}$ & $\begin{array}{l}0.90 \\
0.90 \\
0.91\end{array}$ & $1-6$ & robust \\
\hline
\end{tabular}

Notes: The base (b) coefficient is the estimated coefficient from the regression presented in the text and in Table 2. The high (h) coefficient is the estimated coefficient from the regression with the extreme high bound; the low (l) coefficient is the coefficient from the regression with the extreme lower bound. The Z-variables are the variables included in the base regression that produce the extreme bounds. These variables are numbered in the same order as they are presented in Table 5. The robust/fragile designation indicates whether the variable of interest is considered robust or fragile.

We find that in the DY model only the population growth rate, variable $n$, is proven to be fragile. This is not surprising, since, as previously discussed, observations for this variable not only reflect diminishing returns to labor and fertility choices, but also are strongly affected by migration between regions. Thus, the variable is expected to correlate with other independent and condition variables. All other coefficients are of the expected sign and significant in extreme bounds and thus considered robust. It is noteworthy that most variables were already in ${ }^{15}$ Richardson (1977) proffers a more thorough presentation of different kinds of agglomeration and spatial economies and their measurement. 
their extreme bounds in the base equation. Adding several other variables to the equation only manages to decrease the absolute values of the coefficients.

In the employment equation, the dependencies between variables were not found to be as robust as in the growth equation. Table $4 \mathrm{~b}$ provides the EBA, using the same condition variables as in the previous analysis.

TABLE $4 b$

Sensitivity Results for Variables in Augmented M-R-W Model Dependent Variable: Difference of Regional Employment Level, 1973-1996

\begin{tabular}{|c|c|c|c|c|c|c|}
\hline I-variable & Coefficient & $\begin{array}{l}\text { Standard } \\
\text { Error }\end{array}$ & t-statistic & $\mathrm{R}^{2}$ & $\begin{array}{c}\mathrm{Z}- \\
\text { variables }\end{array}$ & $\begin{array}{c}\text { Robust/ } \\
\text { Fragile }\end{array}$ \\
\hline $\mathrm{n}$ & $\begin{array}{l}\text { h: } 0.045638 \\
\text { b: } 0.035328 \\
\text { l: } 0.025545\end{array}$ & $\begin{array}{l}0.011928 \\
0.011403 \\
0.016700\end{array}$ & $\begin{array}{l}3.83 \\
3.10 \\
1.53\end{array}$ & $\begin{array}{l}0.93 \\
0.92 \\
0.96\end{array}$ & $\begin{array}{l}1-3 \\
1-7\end{array}$ & fragile \\
\hline$s_{k}$ & $\begin{array}{l}\text { h: }-0.265429 \\
\text { b: }-0.308400 \\
\text { l: }-0.540285\end{array}$ & $\begin{array}{l}0.115114 \\
0.104351 \\
0.128868\end{array}$ & $\begin{array}{l}-2.31 \\
-2.96 \\
-4.19\end{array}$ & $\begin{array}{l}0.92 \\
0.92 \\
0.91\end{array}$ & $\begin{array}{l}1-2 \\
1-6\end{array}$ & robust \\
\hline$s_{h}$ & $\begin{array}{l}\text { h: } 0.687423 \\
\text { b: } 0.416339 \\
\text { l: } 0.311164 \\
\end{array}$ & $\begin{array}{l}0.282201 \\
0.287045 \\
0.282780\end{array}$ & $\begin{array}{l}2.44 \\
1.45 \\
1.10 \\
\end{array}$ & $\begin{array}{l}0.96 \\
0.92 \\
0.93\end{array}$ & $\begin{array}{l}1-6 \\
1-3\end{array}$ & fragile $^{a}$ \\
\hline$\overline{e_{t-1}}$ & $\begin{array}{l}\text { h: }-0.766821 \\
\text { b: }-0.860966 \\
\text { l: }-0.877678\end{array}$ & $\begin{array}{l}0.171538 \\
0.168210 \\
0.170058\end{array}$ & $\begin{array}{l}-4.47 \\
-5.12 \\
-5.16\end{array}$ & $\begin{array}{l}0.92 \\
0.92 \\
0.96\end{array}$ & $\begin{array}{l}1 \\
1-7\end{array}$ & robust \\
\hline pp & $\begin{array}{l}\text { h: }-0.089005 \\
\text { b: }-0.066882 \\
\text { l: }-0.044717\end{array}$ & $\begin{array}{l}0.055438 \\
0.055868 \\
0.057583\end{array}$ & $\begin{array}{l}-1.61 \\
-1.20 \\
-0.78\end{array}$ & $\begin{array}{l}0.92 \\
0.92 \\
0.94\end{array}$ & $\begin{array}{l}1 \\
1-4\end{array}$ & fragile $^{a}$ \\
\hline$\overline{\mathrm{pc}}$ & $\begin{array}{l}\text { h: } 0.001669 \\
\text { b: } 0.001669 \\
\text { l: }-0.000471\end{array}$ & $\begin{array}{l}0.000299 \\
0.000299 \\
0.000631\end{array}$ & $\begin{array}{r}5.58 \\
5.58 \\
-0.75\end{array}$ & $\begin{array}{l}0.92 \\
0.92 \\
0.96\end{array}$ & $1-7$ & fragile \\
\hline ps & $\begin{array}{l}\text { h: }-0.090846 \\
\text { b: }-0.134093 \\
\text { l: }-0.134093\end{array}$ & $\begin{array}{l}0.041972 \\
0.035707 \\
0.035707\end{array}$ & $\begin{array}{l}-2.16 \\
-3.76 \\
-3.76\end{array}$ & $\begin{array}{l}0.93 \\
0.92 \\
0.92\end{array}$ & $1-3$ & robust \\
\hline
\end{tabular}

Notes: The base (b) coefficient is the estimated coefficient from the regression presented in the text and in Table 2. The high $(\mathrm{h})$ coefficient is the estimated coefficient from the regression with the extreme high bound; the low (l) coefficient is the coefficient from the regression with the extreme lower bound. The Z-variables are the variables included in the base regression that produce the extreme bounds. These variables are numbered in the same order as they are presented in Table 5. The robust/fragile designation indicates whether the variable of interest is considered robust or fragile.

aThe coefficient is insignificant already with only the I-variables included.

The results show how only physical capital, the convergence factor, $e_{t-1}$, and the political variable, ps, were found to have robust negative partial correlation to employment. Already in the basic model we did not have significant parameter estimates for human capital and primary production, but now estimates of population growth and public capital were found to fragile as well. As the SolowSwan type model is never really intended to explain employment, this is not surprising. Instead, it accurately indicates how a model with statistically significant or almost significant parameter estimates with the expected sign and high coefficient of determination may prove spurious when submitted to proper sensitivity testing. The above result gives reason to abandon our model for explaining employment (Table $4 \mathrm{~b}$ ), but, conversely, it increases our confidence in the growth model (Table $4 a$ ), which was proven to be very robust. 
When we turn our attention to variables in the condition set, we find in Table 5 that their partial correlations with output growth are all fragile. On the other hand, all partial correlations are of expected sign, i.e., proportion of workforce with tertiary education is positively correlated with the growth of output, as well as the level of highway and railroad networks of a region. Furthermore, the correlation between output growth and social expenditure, public debt, and the local income tax rate is negative. Finally, partial correlation with population density and output growth is found positive. Thus, all of these condition variables have the kind of elasticity with respect to output growth as the theory would indicate, but these elasticities cannot be precisely estimated. Hence, it is reasonable to exclude them because the overall performance of the model will not decline.

TABLE 5

Sensitivity Results for Variables in the Condition Set

\begin{tabular}{|c|c|c|c|c|c|c|}
\hline Z-variable & $\begin{array}{l}\text { Extreme } \\
\text { Bound }\end{array}$ & $\begin{array}{l}\text { Standard } \\
\text { Error }\end{array}$ & t-statistic & $\mathrm{R}^{2}$ & $\begin{array}{c}\text { Other } \\
\text { variables }\end{array}$ & $\begin{array}{c}\text { Robust/ } \\
\text { Fragile }\end{array}$ \\
\hline Tertiary & h: 0.014505 & 0.009201 & 1.58 & 0.91 & $2-5$ & \\
\hline Education & 1: 0.010530 & 0.007098 & 1.48 & 0.91 & & fragile \\
\hline \multirow[t]{2}{*}{ Highways } & h: 0.339307 & 0.536234 & 0.63 & 0.91 & $1,3-7$ & \\
\hline & 1: 0.043884 & 0.182014 & 0.24 & 0.91 & 1 & fragile \\
\hline \multirow[t]{2}{*}{ Railroads } & h: 0.068975 & 0.088807 & 0.78 & 0.91 & $1-2,4-7$ & \\
\hline & l: 0.022360 & 0.060024 & 0.37 & 0.91 & $1-2$ & fragile \\
\hline Social & $h:-0.000002$ & 0.000009 & -0.22 & 0.91 & $1-3,5-6$ & \\
\hline Captial & 1: -0.000004 & 0.000008 & -0.51 & 0.91 & $1-3,5$ & fragile \\
\hline Public & $h:-0.000004$ & 0.000010 & -0.40 & 0.91 & $1-4,6$ & \\
\hline Debt & l: -0.000007 & 0.000009 & -0.75 & 0.91 & $1-4$ & fragile \\
\hline Income & h: -0.008900 & 0.013380 & -0.67 & 0.91 & $1-5$ & \\
\hline Tax Rate & l: -0.009093 & 0.014375 & -0.63 & 0.91 & $1-5,7$ & fragile \\
\hline Population & h: 0.000026 & 0.000559 & 0.05 & 0.91 & $1-6$ & \\
\hline Density & 1: 0.000026 & 0.000559 & 0.05 & 0.91 & $1-6$ & fragile \\
\hline
\end{tabular}

Notes: The high (h) coefficient is the estimated coefficient from the regression with the extreme high bound; the low (l) coefficient is the coefficient from the regression with the extreme lower bound. The other variables are the Z-variables included in the regression that produce the extreme bounds. These variables are numbered in the same order as they are presented here. The robust/fragile designation indicates whether the variable of interest is considered robust or fragile.

\section{Testing Growth Estimation with Per Employee Figures}

In comparison with the above results, estimations that in a way test the combined effects of dependencies observed with the DY model and the DE model were also run, that is, instead of per capita output growth and employment growth, we estimated output per employee growth rates across the provinces. ${ }^{16}$ By means of this model, the partial correlation between left-wing politics and output growth was now found to be fragile. We interpret this to indicate that out political variable is not necessarily entirely exogenous, but may be contaminated to some degree by the simultaneity problem after all. This may be caused by the fact that higher unemployment and lower per capita income growth enhance the public support for left-wing parties, and, at the same time, the mass departure of unemployed persons raises output per employee figures.

${ }^{16}$ These results are available from the author upon request. 
On the other hand, all the other I-variables in this model were found to be robust and we have strong reason to believe that this dependency is based on the factors of diminishing returns to each input factor as can be derived from the neoclassical theory, i.e., we find that the average investment rate, human and public capital accumulation, the labor force growth rate, and the structure of production are effective predictors of the output growth rate. Finally, the strong evidence in favor of conditional convergence across regions in the long run argues against first-generation models of endogenous growth. Still, the results do not rule out convergence development based on R\&D or the diffusion of technology. For instance, Bernard and Jones (1996), Dosi, Pavitt, and Soete (1990), Fagerberg (1988), McCombie (1982), Kocherlakota and Yi (1995), and Tamura (1991) have derived similar convergence phenomena to be in line with premises of endogenous type growth models.

\section{CONCLUSION AND DISCUSSION}

\section{Relevance of the Different Forms of Capital}

The empirical analysis presented above provides strong qualitative support for the neoclassical model of economic growth across Finnish regions. In the long run, differences in investment rate, education, population growth, public capital, and political and production structures explain the largest part of crossregional differences in output per capita growth figures. There is also reason to expect that the model will provide the best framework for understanding how these determinants influence the region's long-run level of economic growth. Still, the key role played by human and social capital and the initial conditions (convergence factor) suggests the need to examine more directly the accumulation of human capital (which was found to be very difficult to model without measurement error) as well as infrastructure factors. For instance, studies of the growth effects of the public infrastructure in the U.S.A. have been contradictory (e.g., Evans and Karras 1996; Holtz-Eakin 1996; Nadiri and Mamuneas 1996). A more thorough understanding of the interlinkage among physical, human, and social capital investments within the system of regions appears to be an important area for further research, especially in the present European and World economy that is increasingly showing signs of economic integration.

In light of our empirical evidence, we may conclude that the primary sources of regional GDP growth in Finland originate from private and public investments. As discussed in Eicher and Turnovsky (1999), the type of investmentbased growth model used in this study differs from $R E D$-based growth models mainly in the emphasis it places on how much growth depends upon the existence and nature of production externalities. While the creation and diffusion of new technology and production externalities may count quite significantly among heterogeneous group of countries, it is likely to warrant far less importance among sufficiently homogeneous regions within a single country. We have every reason to assume that Finnish regions have access to similar technology and assert 
sufficiently similar structural characteristics of the economy, such as fundamental productivity of capital, the endogenous accumulation of knowledge, consumers' tastes, and general preferences of economic policy. This is why we find the neoclassical growth model far more suitable for the analysis of the characteristics of the growth process among Finnish regions than may be the case when one is analyzing several countries or a group of relatively heterogeneous multinational regions.

\section{Factors Not Found Significant to Growth}

On the other hand, it was important to observe which possible growth factors were not found to have any significant impact on regional growth rates. It is worth pointing out that any such conclusion that states that these variables exert no effect on growth because this effect is imprecisely measured might result in Type II error. But we have reason to believe that the importance of these variables within this model is limited and/or their effect is already reflected by other variables included in the model. First of all, partial correlation between the growth of tertiary education and output growth was found positive, but the significance of the results remained slightly under the critical $5 \%$ level. This indicates the possibility that the measure of human capital could be elaborated with different aspects of education and work experience. However, the degree of secondary education probably is the best single indicator of human capital.

Second, we did not find statistically significant traces of classical spatial factors of growth. That is, the increased presence of highways and railroads was not found to have permanent growth-accelerating effects, although estimated parameters for these variables were weakly positive. The transportation network is bound to play an essential role in the earlier developmental stage of the national economy, but within a homogeneous group of regions in a highly industrialized country one can assume that they no longer play so notable a role. Following Adams (1981), one may assume that even this simple modeling has adequately analyzed how the integration of the national transportation network in Finland had already in the 1970s reached a stage of maturity, with the economy characterized by a high level of mass consumption. Expanding the highway and railroad network then is no longer vitally important for the stages of economic development. It is known that proximity to transportation is still important, for example, for small business start-ups, as well as for local development. Nevertheless, its observable growth-accelerating effects among large and homogeneous economic regions seem limited.

Third, the negative growth effect of social spending was found to be very imprecisely determined and is likely to be contaminated by the simultaneity problem, that is, social spending is larger in regions where unemployment problems are increased. As a result, despite its theoretical basis, the assumed negative correlation between output growth and local financial factors (public debt and tax rate) was not found to be significantly confirmed. The width of the public sector 
and the level of economic development of a region are correlated and this way the dependency is affected by the simultaneity problem. Thus, the results presented above indicate that this interdependency probably has no great importance for the pace of economic growth when compared to the more traditional and crucial variables of the neoclassical model.

Finally, agglomeration factors measured by means of population density were found to have only an insignificant positive correlation with output growth. This dependency is presumably already perceived with the variable of proportion of primary production, which maintains constant differences between urban and rural areas.

\section{Policy Implications}

As implications for economic policy, the results strongly suggest that raising the investment rate will indeed raise productivity. A permanent increase in the investment rate (or in the level of technology) increases the steady-state capital stock and, since the economy is then further away from its steady state, it will grow faster. Within the basic neoclassical context, this will lead to only "temporarily" faster growth, since the economy will eventually reach its steady state, with the levels of $\mathbf{k}$ and $y$ permanently higher, but the per capita growth rates adjusted to zero. Since numerical experiments with benchmark values, as reported in several textbooks, conclude that this implied steady state is still decades away, it is quite safe to assume that the increased accumulation of different types of capital will increase economic growth in the foreseeable future. Thus, a key point is the finding that there is a robust dependency between regional investment rates and economic growth over a finite time period.

The strong significance of human and public capital also indicates that a higher savings rate in the economy has a larger impact on income per capita than the textbook Solow model would imply. This is because higher income in steady state leads not only to a higher level of physical capital but to a higher level of public and human capital as well. This result also has important implications for the dynamics of the economy below its steady state, since the assumed convergence between regions now occurs much more slowly than the Solow model suggests. If we abandon the assumption of an identical production function across time and assume that the production function has over time become somewhat more human and public capital intensive, this may explain the often-suggested phenomenon that the convergence between regions has slowed during the past decade.

As far as further implications for regional policy, we must note the statistically significant as well as positive partial correlation between output and population growth found in Finland (due to migration). This implies that the effects of physical, human, and public capital investment are not symmetric for regions. Higher marginal products of labor will lead to improved real wages, and the high mobility of labor will, at least in the short term, raise the possibility that each 
region may not reap the benefits of its human capital investments. Human capital is thus likely to concentrate in those areas most abundant with physical and public capital. This in turn may partially explain the observed unrepresentative behavior of the capital area in Finland.

One may infer that preferential policies foster more rapid accumulation of different forms of capital. The results of this study indicate that the neoclassical model is consistent with the empirical evidence if one acknowledges the importance of human and public capital in addition to the traditional physical capital. The augmented model presented here singles out these new forms of capital as the principal engine of the growth process, emphasizing the role of human capital formation and government capital accumulation. It is noteworthy how all of these policy implications can also be interpreted to be in line with policy recommendations derived from so-called AK models of the new growth theory, which emphasize technological development in the absence of diminishing returns, for instance, due to learning-by-doing and knowledge spillovers. That is why we need not necessarily regard the competing neoclassical and endogenous growth models as utterly conflicting and, regarding their comprehensive framework, even hostile to one another. The more fruitful approach might consider them primarily as complementary to each other and see them differing only vis-à-vis the emphasis and interpretation they tend to have on different aspects of the longterm growth process.

\section{REFERENCES}

Adams, J. Transport Planning, Vision and Practice. London: Routledge, 1981.

Andrés, J., R. Doménech, and C. Molinas. "Growth and Convergence in OECD Countries: A Closer Look." In B. van Ark and N. Crafts (eds.) Quantitative Aspects of Post-War European Economic Growth. Cambridge: Cambridge University Press, 1996.

Arellano, M., and S. Bond. "Some Tests of Specification for Panel Data: Monte Carlo Evidence and an Application to Employment Equations." Review of Economic Studies 58 (1991), 277-297.

Aschauer, D.A. "Output and Employment Effects of Public Capital." Jerome Levy Economics Institute, Working Paper No. 190. Annandale-on-Hudson, N.Y., 1997.

Backus, D., P. Kehoe, and T. Kehoe. "In Search of Scale Effects in Trade and Growth." Journal of Econometric Theory 58 (1992), 377-409.

Baltagi, B.H. "Pooling: An Experimental Study of Alternative Testing and Estimation Procedures in a Two-Way Error Components Model." Journal of Econometrics 17 (1981), 21-49.

Barro, R and X. Sala-i-Martin. "Convergence." Journal of Political Economy 100 (1992), 223-251.

Baumol, W. "Macroeconomics of Unbalanced Growth: An Anatomy of Urban Crisis." American Economic Review 57 (1967), 415-426. 
Beck, N., and J.N. Katz. "What To Do (and Not Do) with Time-Series Cross-Section Data." American Political Science Review 89 (1995), 634-647.

Belsley, D.A., E. Kuh, and R.E. Welsch. Regression Diagnostics: Identifying Influential Data and Sources of Collinearity. New York: John Wiley \& Sons, 1980.

Bernard, A.B., and C.I. Jones. "Productivity across Industries and Countries: Time Series Theory and Evidence." Review of Economics and Statistics 78 (1996), 135-146.

Breusch, T.S., and A.R. Pagan. "A Simple Test for Heteroskedasticity and Random Coefficient Variation." Econometrica 47 (1979), 1287-1294.

Buse, A. "Goodness of Fit in Generalized Least Squares Estimation." American Statistician 27 (1973), 106-108.

Chatterji, M. "Tertiary Education and Economic Growth." Regional Studies 32 (1998), 349-354.

Chow, G.C. "Tests of Equality between Sets of Coefficients in Two Linear Regressions." Econometrica 28 (1960), 591-605.

Cook, R.D. "Detection of Influential Observations in Linear Regressions." Technometrics 19 (1977), 15-18.

Crafts, N., and G. Toniolo. "Postwar Growth: An Overview." In N. Crafts and G. Toniolo (eds.) Economic Growth in Europe since 1945. Cambridge: Cambridge University Press, 1996.

Dosi, G., K. Pavitt, and L. Soete. The Economics of Technical Change and International Trade. New York: Harvester Wheatsheaf, 1990.

Durbin, J. "Testing for Serial Correlation in Least-Squares Regression When Some of the Regressors Are Lagged Dependent Variables." Econometrica 38 (1970), 410-421.

Eicher, T.S., and S.J. Turnovsky. "Non-Scale Models of Economic Growth." The Economic Journal 109 (1999), 394-415.

Evans, P., and G. Karras. "Do Economies Converge? Evidence from a Panel of U.S. States." Review of Economics and Statistics 78 (1996), 384-388.

Fagerberg, J. "Why growth Rates Differ." In G. Dosi et al. (eds.) Technical Change and Economic Theory. London: Pinter Publishers, 1988.

Godfrey, L.G. "Testing for Multiplicative Heteroskedasticity." Journal of Econometrics 8 (1978), 227-236.

Hansen, L.P. "Large Sample Properties of Generalized Method of Moment Estimators." Econometrica 50 (1992), 1029-1054.

Harris, J.R., and M.P. Todaro. "Migration, Unemployment and Development: A Two-Sector Analysis." The American Economic Review 51 (1970), 126-143.

Holtz-Eakin, D. "Public-Sector Capital and the Productivity Puzzle." Review of Economics and Statistics 78 (1996), 12-21.

- "Solow and the States: Capital Accumulation, Productivity, and Economic Growth." National Tax Journal 46 (1993), 425-439.

Islam, N. "Growth Empirics: A Panel Data Approach." Quarterly Journal of Economics 110 (1995), 1127-1170. 
Jarque, C.M., and A.K. Bera. "Efficient Tests for Normality, Homoscedasticity and Serial Independence of Regression Residuals." Economics Letters 6 (1980), 255-259.

Jones, C. "Time Series Tests of Endogenous Growth Models." Quarterly Journal of Economics 110 (1995), 495-527.

Kangasharju, A. Regional Economic Differences in Finland: Variations in Income Growth and Firm Formation. Pellervo Economic Research Institute Publication No. 17. Helsinki: Hakapaino, 1998.

Kmenta, J. Elements of Econometrics. 2d ed. New York: Macmillan, 1986.

Knight, M., N. Loyaza, and D. Villanueva. "Testing the Neoclassical Theory of Economic Growth." IMF Staff Papers 40 (1993), 512-541.

. "Testing the Neoclassical Theory of Economic Growth." IMF Working Paper 92/106, 1992.

Kocherlekota, N.R., and K-M. Yi. "Can Convergence Regressions Distinguish between Exogenous and Endogenous Growth Models?" Economics Letters 49 (1995), 211-215.

Lahti, R. Suomen Valtakunnallinen Integroituminen [National Integration in Finland]. Tampere: University of Tampere, Publications in Department of Regional Studies, B:49, 1988.

Leamer, E.E. "Let's Take the Con Out of Econometrics." American Economic Review 73 (1983), 31-43.

Levine, R., and D. Renelt. "A Sensitivity Analysis of Cross-Country Growth Regressions." American Economic Review 82 (1992), 942-963.

Loikkanen, H.A., S. Laakso, and R. Sullström. Regional Income Differences in Finland, 1966-96. Government Institute for Economic Research, Publication No. C 181, 1998.

Mäki-Arvela, P. "Regional Convergence and Inequality in Finland, 1927-1996." Manuscript, 2002.

Mankiw, N.G. "The Growth of Nations." Brookings Papers on Economic Activity 1 (1995), 275-326.

Mankiw, N.G., D. Romer, and D.N. Weil. "A Contribution to the Empirics of Economic Growth." Quarterly Journal of Economics 108 (1992), 407-437.

McCombie, J.S.L. "A Synoptic View of Regional Growth and Unemployment: I The Neoclassical Theory." Urban Studies 25 (1988), 276-281.

. "How Important is the Spatial Diffusion of Innovations in Explaining Regional Growth Rate Disparities?" Urban Studies 19 (1982), 377-382.

McCullum, B.T. "Neoclassical vs. Endogenous Growth Analysis: An Overview." Federal Reserve Bank of Richmond Economic Quarterly 82 (1996), 41-71.

Nadiri, M.I., and T.P. Mamuneas. "The Effects of Public Infrastructure and R\&D Capital on the Cost Structure and Performance of U.S. Manufacturing Industries." Review of Economics and Statistics 78 (1996), 22-37.

Parks, R.W. "Efficient Estimation of a System of Regression Equations when Disturbances are both Serially and Contemporaneously Correlated." Journal of the American Statistical Association 62 (1967), 500-509. 
Pekkala, S. "Regional Convergence across the Finnish Provinces and Subregions." Finnish Economic Papers 12 (1999), 28-40.

Ramsey, J.B. "Tests for Specification Errors in Classical Linear Least Squares Regression Analysis." Journal of the Royal Statistical Society Ser. B, Pt. 2 (1969), 350-371.

Richardson, H.W. Regional Growth Theory. 2n ed. London: Macmillan, 1977.

Sala-i-Martin, X. "The Classical Approach to Convergence Analysis." The Economic Journal 106 (1996), 1019-1036.

Sargan, J.D. "Some Tests of Dynamic Specification for a Single Equation." Econometrica 48 (1980), 879-897.

Tamura, R. "Income Convergence in an Endogenous Growth Model." Journal of Political Economy 99 (1991), 522-540.

Temple, J. "The New Growth Evidence." Journal of Economic Literature 37 (1999), 112-156.

. "Robustness Tests of the Augmented Solow Model." Journal of Applied Econometrics 13 (1998), 361-375. 